\title{
AT THE DRAG BALL IN MY MIND YOU ARE WEARING BLUE ORGANZA
}

It is 1962 and you are serving damply elegant southern Cuban Missile Crisis glamour and outside the cotillion children are running on the lawn with sparklers. In my mind your dress is so blue. In my mind you are so beautiful your male body cannot contain beauty and my mind unhinges and releases you to History. I imagine for you lives just a little unlike yours and I marry you to me and I put you in places I would like to see you with people I think you might like. It is 1962 and you are making your debut under the name Starlight LaBelle Rue, there is no shade in this dance palace, you are a hot small star on stage glossy with sweat. I watch, wet from anticipation and fear of cosmic retribution and outside Khrushchev is bearing down like a comet and our mutual destruction will be set to Paul Anka: dance on, little girl, in my mind you are a star. Your drag mother raised you up right, I think as we reunite by the vermilion sofas in the powder room where we blush together. You are a Winter in autumn in a cotillion ball for beautiful boys, outcasts swathed in extra yardage, taffetas, and tulles. In my mind you are offering me a tall glass of water. My real mother cannot quilt you tell me in drag voice, and I pretend not to be stunned by the depth of your regret. In bed I want to paint breasts on your chest right now, in the shape you showed me in 1962, half-moons and crescents crowning pectorals more perfect than my own breasts were when I was seventeen and free. We are always in bed in my mind, lover, naked on Amish quilts with your name stitched on a corner. Make me up, I whisper but instead we cook deer steaks and create an alternate history for Starlight where we put DJ in front of her name and it is 1997 and she is a boy and she is you and you are seventeen and you are laying down beats for your friends and you never went to New Orleans except for a Christian youth conference. But you look so fine in blue in my mind! Like a glaciating landmass in sparkle-sheer sandalfoot nylons when I dress you up before we do it but the first time we met for real you were wearing a blue polo shirt and drinking a beer and you were serving farm-boy Indiana realness alongside ivory tower fuck-toy realness alongside PBR and out on a curb you smoked a cigarette and threw me shade: You look uncomfortable smoking and I hated you because you were right. 